\title{
A Systematic Biomedical Perspective on COVID-19 Pandemic: From Detection to Vaccination
}

\author{
Jan. M. Mir ${ }^{*}{ }^{\circledR}$, Rais A. Wani, Hyqa John, Ejaz A. Kambay, Bashir A. Malik, Sheikh A. Majid ${ }^{\circledR}$, Aabid \\ H. Shalla
}

Department of Chemistry, Islamic University of Science and Technology, Awantipora, India

E-mail:mirjanmohammad@gmail.com

Received: 8 September 2021; Revised: 30 November 2021; Accepted: 9 December 2021

\begin{abstract}
The year 2020 witnessed a challenging period for worldwide scientists to find a suitable treatment for the deadly novel coronavirus infectious disease-2019 (nCOVID or COVID-19). The entire scientific community has been eager to develop effective vaccines and medicine against COVID-19. Despite the fact of administration of vaccination in several countries across the globe, the drug repurposing of several antiviral compounds yielded satisfactory results in recovering the affected people. As it is a known fact that vaccination alone is not the end of this pandemic, but the final treatment in terms of drugs/medicines specific to this disease is yet underway. It looks worthy to present a literature survey based on the collective information related to the drug candidates that have been repurposed, the respective theoretical evaluation, and some of the effective therapies usable in treating COVID-19. This review also describes diagnosis and vaccination availed so far. Therefore, a sequential literature extract is hereby presented starting from the detection, going through virulence, drug repositioning, virtual screening, and the final destination in the form of vaccine development. A few commercially available vaccines have also been introduced. Based on the survey, it is clear that the entire world must remain alert for any future pandemic keeping in view the successful and unsuccessful efforts practiced in the COVID-19 pandemic.
\end{abstract}

Keywords: corona, COVID-19, drug repurposing, docking, therapies, density functional theory

\section{Introduction}

A large number of causalities happened worldwide with the outbreak of novel coronavirus infectious disease-2019 (nCOVID or COVID-19). After being declared as a pandemic, an emergency was declared globally in response to the rapid transmission and increased number of deaths. Even though vaccination for coronavirus has been started, but no specific treatment has been yet found for this disease. Though the human immune system is the real defense to combat this disease, the use of some known antiviral drugs has been repurposed for the treatment of coronavirus infection [1].

Due to the rapid transmitting feature, high pathogenicity and genetic composition matching with severe acute respiratory syndrome coronavirus 1 (SARS-CoV-1), the infection has been termed as severe acute respiratory syndrome coronavirus 2 (SARS-CoV-2) [2]. The actual origin of this dreadful virus is yet unknown, though the human-to-human transfer of novel coronavirus is widely known. Therefore, preventive measures in the form of social distancing and sanitization received immense attention worldwide. Despite these strategies depending on geographical location and

Copyright (C2021 Jan M. Mir, et al.

DOI: https://doi.org/10.37256/acbr.1120221146

This is an open-access article distributed under a CC BY license

(Creative Commons Attribution 4.0 International License)

https://creativecommons.org/licenses/by/4.0/ 
living standards, but have proven helpful in breaking the spreading chain of this infection [3]. Meanwhile, antiviral and anti-inflammatory drugs have been repurposed as a way to treat infected people. Hence, due to the absence of the availability of any COVID-19 specific drug, the use of some broad-spectrum antiviral drugs has been practiced worldwide and is generally referred to as drug repurposing.

The innate responsive property of the human body towards microbial invasions, heat shock, or toxin intervention is mainly dealt with immune system, expresses in some symptomatic forms including inflammation, color change, heat, etc. The inflammation is usually associated with the releasing of histamine, bradykinin, and prostaglandins by the affected tissue or cellular region, inducing blood vessels to leak fluid into the belonging tissues and finally causing swelling in the respective portion. Non-steroidal anti-inflammatory drugs (NSAIDs) are usually administered to control and reduce inflammation. These administered drugs include both the types of inhibitors viz., selective as well as nonselective. Rofecoxib, valdecoxib, celecoxib, etc., are the selective cyclooxygenase-2 (COX2) inhibitors, and on the other hand ibuprofen, aspirin, diclofenac, and naproxen are non-selective. In COVID-19, these mechanistic pathways in selecting suitable drugs for the treatment have raised concerns over the possible increasing adverse effects [4, 5]. Several shreds of evidence indicate NSAID's role for COVID-19 treatment, however, in respect to this viral strain and the mutations that go on in the virus, it needs to be controlled under high order precautions [6]. Many antimalarial drugs (like chloroquine) [7] and several other broad-spectrum antiviral drugs have been repurposed to treat infected people. This antiviral mechanism has been diagnosed with increased endosomal $\mathrm{pH}$ and inhibition of the glycosylation of severe acute respiratory syndrome coronavirus (SARS-CoV) [8, 9]. Therefore, chloroquine, arbidol, dexamethasone, etc., have found emergency use against the infection, and satisfactory results were gained [10-14].

In the conspicuous fascination towards COVID-19 investigations and our continuous interest, this review was aimed to sum up the COVID-19 pandemic sequential stages to derive the past, present and future directions of this disease. The challenges that the analytical front has met during the pandemic, drug repurposing, theoretical scientific role, and the stage of vaccination have been highlighted in this article.

\section{COVID-19 pandemic outbreak and SARS-CoV-2 virulence}

In December 2019, the novel coronavirus infection was first detected in Wuhan, Hubei Province, China. As of now this infectious disease is widely known as COVID-19 or nCOVID and has been widely spread in the whole world [15]. On 31st December 2019, high authorities of China alerted World Health Organization (WHO) with an alarming signal conveying the outbreak of a new strain of coronavirus, responsible for severe illness similar to SARS-CoV-1, and was hence named as SARS-CoV-2. COVID-19 is currently considered a high transmitting infectious disease. Though the actual source of this infection is unknown yet, the high communicability and millions of deaths by this disease defeated the whole world. Albeit the dynamics are not clear yet, several assumptions have been made showing the virus to have an animal origin [16].

The coronavirus has been found to have an elliptic or round shape and is mostly referred to as pleomorphic (in microbiology, pleomorphic microorganism is the capability to change morphology, functional status, or modes of reproduction with respect to environmental conditions). The virus has a diameter of 60-140 nm approximately. Generally, coronaviruses are ultraviolet (UV) and heat-sensitive. The genetic analysis has shown a resemblance of $86 \%$ of the whole genome of SARS-CoV-2 with SARS-CoV-1 [17]. Studies conducted on seeking the mechanistic details of SARS-CoV-2 virulence have confirmed the respective affinity towards the functional behavior of the structural proteins (SP) and nonstructural proteins (NSPs). For example, the underlined research indicated that NSPs possess the ability to impair and affect the innate immune response of the host [18].

Figure 1 displays the structural diagram of the virus along with the SP and NSPs parts. The main part of the virus involved in pathogenicity is its envelope because it is the key supporting assembly for viral release. Secondly, the biological interaction through specific enzyme intervention viz., the angiotensin-converting enzyme-2 (ACE2) located on the lower respiratory tract cells of humans, has a direct link for receptors to conduct endocytosis for SARS-CoV-2 in COVID-19 [19]. Among the different structural components of the virus, the constituent spike (S) glycoprotein mainly consists of S1 and S2 subunits. The S protein homotrimers are arranged on the surface of the virus wholly termed as envelop that represents the leading ink used for host receptor susceptibility. The S2 subunit is highly conserving for being a site of fusion peptide along with the transmembrane domain and the cytoplasmic region. Therefore, for 
designing anti-coronavirus agents, S2 is the main target to deactivate. Other SP is found only in COVID-19 causing viruses, including open reading frame (ORF) encoded proteins, ORF3b and ORF8 [20]. The latest research on receptorbinding domain (RBD) part of the virus S proteins reveals efficiently targeting feature of the ACE2 receptors at the molecular level. These receptors have a key role in blood pressure maintenance. The SARS-CoV-2 S protein has got such an effective binding potential with the human cells; such that the entire world community of scientists remarked this as a result of natural selection with no implications of genetically engineered products [21].

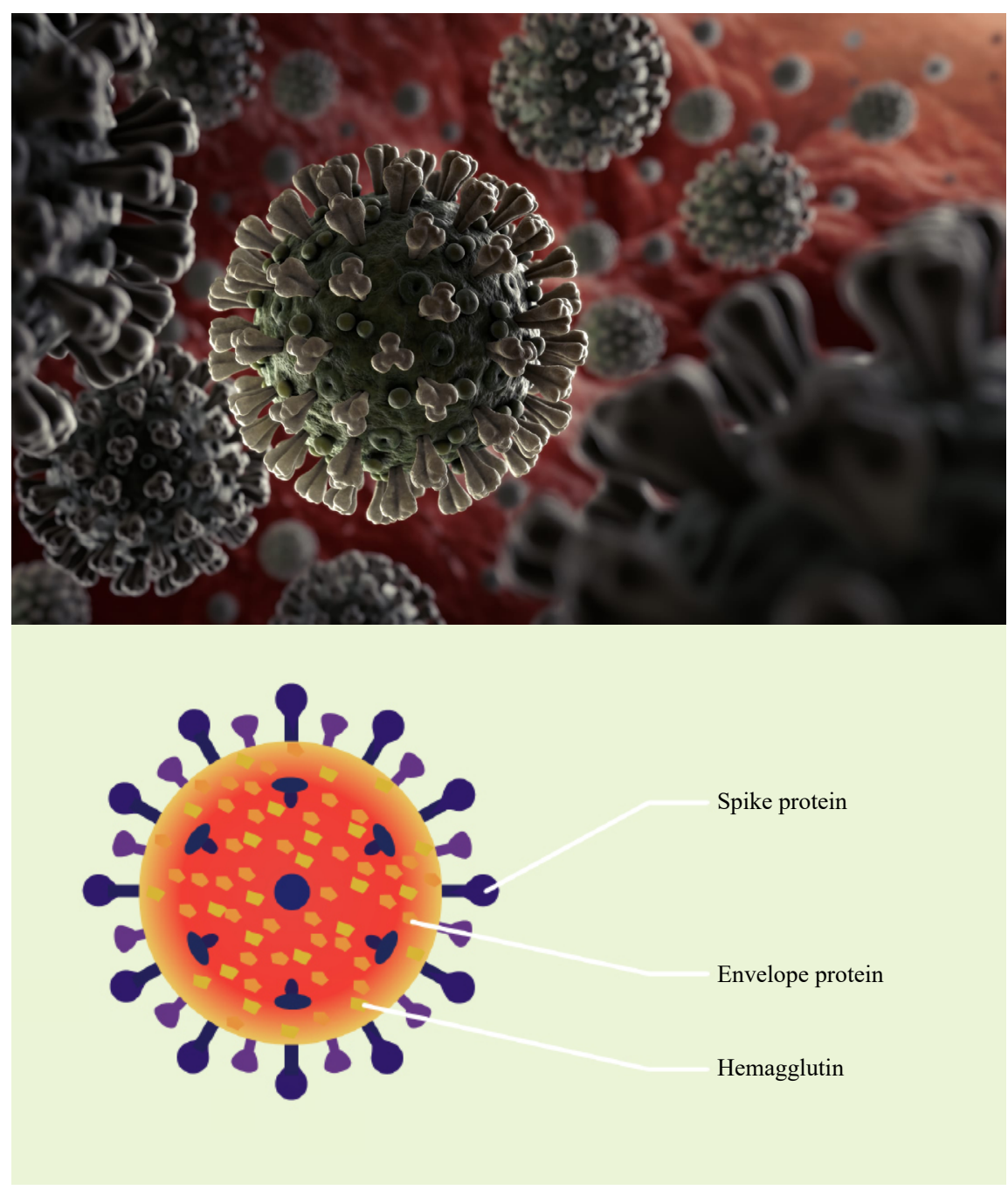

Figure 1. Viral structure of COVID-19 causing virus [22: p.11]

\section{COVID-19 diagnosis}

With the novel coronavirus pandemic, many concerns regarding the detection of this disease have emerged. The COVID-19 diagnosis is usually done using real-time polymerase chain reaction (RT-PCR). RT-PCR method refers to a nuclear-based detection of genetic material present in any sampled substance including a virus. Previous versions of this instrument were principally involving radioactive isotopic effect marking agents to find the information of a particular genetic analyte, but due to subsequent refining isotope labeling was replaced with special markers, most often which are fluorescent dyes. The technique furnishes the results immediately. This technique has found a wide range of use for detecting the novel coronavirus infection. Like drug repurposing for COVID-19, instrumental repurposing in the form of 
RT-PCR which was earlier used for diagnosing Ebola and Zika viral infections supported to a maximum in diagnosing COVID-19 infection [23].

Because of the scarce access to equipment, reagents, and less target specific, the test is not much reliable [2426]. Based on the requirement of accuracy, patient care and medicine, such diagnostics must be less time-consuming and more reliable. Therefore, test sensitivity, cost and time taken by routine techniques have forwarded quests to the scientific community to search for more sensitive and high economic ways of detection. Mass spectrometry, Raman, infrared, etc., like techniques have been suggested to solve these issues [27, 28]. Similarly, biosensing detection based on field-effect transistor (FET) has been suggested as high sensitive diagnostic method using immunological concept [29]. Some coupled techniques like ultra-high-pressure liquid chromatography hyphenated with high-resolution mass spectrometry (UHPLC-HRMS)-based have also been suggested in this context [30]. Therefore, the on-time detection along with clinically satisfied specificity and sensitivity is the most important forefront in COVID-19 detection analysis. It is expected that spectroscopic analysis can be a promising detection way using the potential chemical biomarkers [31, 32].

The expression of proteins or enzymes associated with COVID-19 severity or death could be assigned as markers of the infection. These include D-dimer for blood coagulation, lactate dehydrogenase indicative of cell damage and C-reactive protein showing the inflammatory response. An accumulation of evidence relating to COVID-19 with the severe acute respiratory syndrome (SARS) suggests that protein biomarkers could define these investigations [33]. From the identity of their absorption and emission bands, it can be possible to find the extent of infection. The consistency of different vibrational and rotational modes in bioaerosols like coronavirus has been proposed as useful in presence of a light-sensitive material [34]. In due course, even smartphone-assisted electrochemical signaling has also been suggested as a detective device [35]. Optical theranostics could identify the pulmonary severity of COVID-19 easily [36]. Non-contact nanomaterial-based optical methods have been reported to help in both the detection as well as surface disinfection of coronavirus [37]. Therefore, interaction with light is suitable for both detection as well as disinfection even if present in trace concentrations [37,38].

\section{Antiviral drug repurposing as the treatment option in COVID-19 pandemic}

COVID-19 apocalyptic times witnessed emergency use of known antiviral drugs in addition to other precautionary measures including sanitization and physical distancing. The clinical and nonclinical investigations made in the same period indicate a satisfactory recovery rate using the drugs that were earlier found effective against several viral diseases. This administration of drugs is generally known as drug repurposing. The drugs that found emergency repurposing have been discussed below.

\subsection{Hydroxychloroquine and chloroquine}

After the widespread of COVID-19, many antiviral, anti-inflammatory, and antimalarial drugs were used as emergency medicine [39] because of the unavailability of COVID-19 specific medicine. Despite numerous side effects of hydroxychloroquine, the drug when used in nCOVID patients showed positive results to a considerable extent [40]. In the course of the administration, researchers have been continuously studying the efficacy, safety and other mechanistic pathways involved in treating COVID-19 patients [41]. Results indicate that the hydroxychloroquine-based treatment had reduced the fatality rate among the nCOVID patients as compared to those patients who were not treated with this drug [42]. The administration of zinc supplements and azithromycin in addition to hydroxychloroquine has shown a remarkable increase in the recovery rate [43]. Albeit the safety concern [44-46], this triple-drug combination has been reported as an effective COVID-19 treatment [47]. The repositioning of this drug thus faced several critics for safety purposes [48], but in the drug emergency, chloro- and hydroxychloroquine were tremendously used to treat COVID-19 patients [49]. Both these drugs have been found to change the $\mathrm{pH}$ and create misinformation of viral proteins. The drugs were already in use to treat the different viral diseases like Ebola, influenza, human immunodeficiency virus (HIV), etc. Several mechanistic pathways have been proposed for their antiviral action and certain questions are under investigation [50], but recent studies have revealed that hydroxychloroquine restricts the replication process of the SARS-CoV-2 virus $[51,52]$. 
Other suggestions like inhibition of the importin (IMP $\alpha / \beta 1)$ and acidotropic lipophilic weak base behavior by hydroxychloroquine have also been mentioned in the mechanistic studies. The structures of both forms of chloroquine have been given in Figure 2.

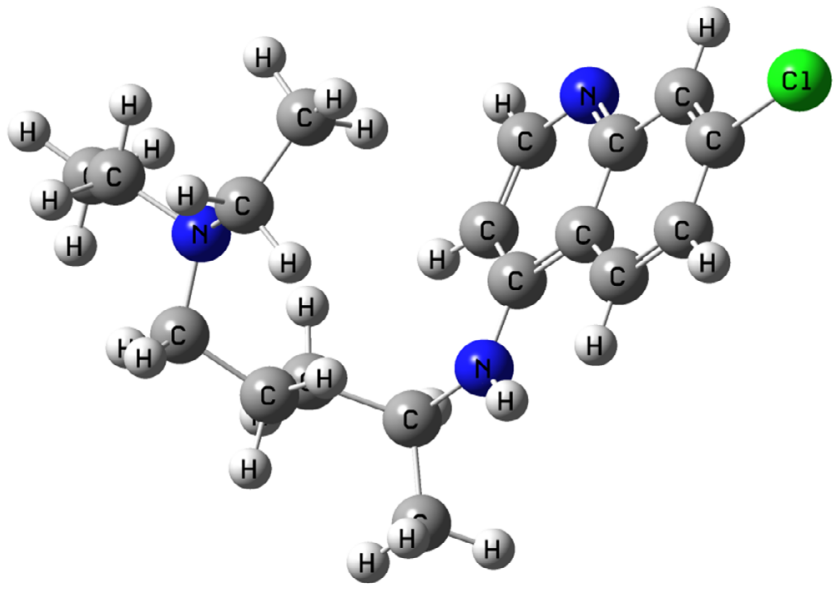

(a)

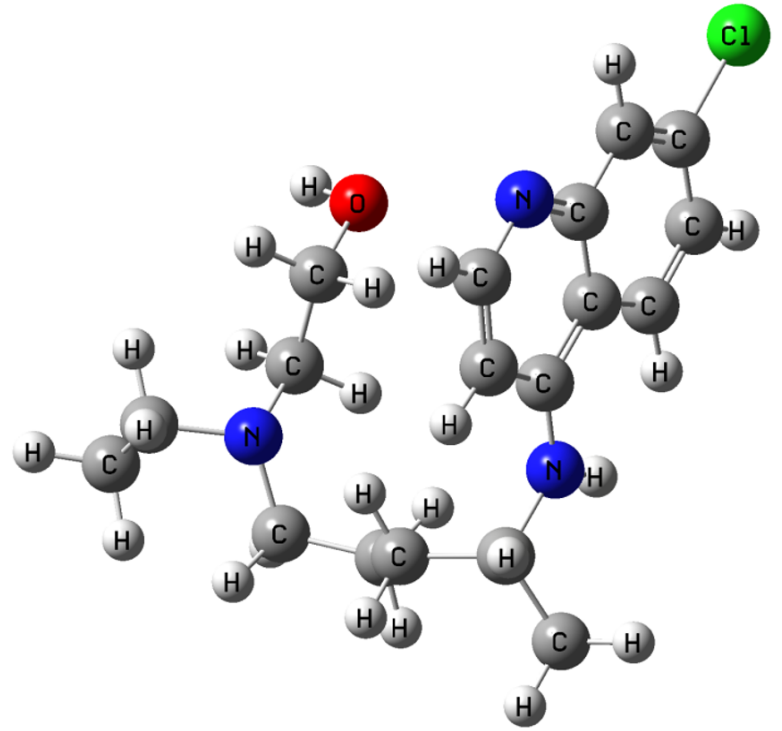

(b)

Figure 2. 3D structures of (a) chloroquine and (b) hydroxychloroquine (Drawn in GaussView5.0)

\subsection{Favipiravir}

Favipiravir represents another significant antiviral drug that is mainly found in oxo and hydroxy forms (Figure 3). This drug has been repurposed for COVID-19 treatment in most countries including India. This antiviral drug is specific to the influenza virus. As prolonged use of this drug increases the uric acid level in blood which in turn affects the kidney functioning, and hence, favipiravir cannot be administered for a long time [53]. The repositioning of favipiravir for nCOVID has shown a good response when compared with the repurposing of other antivirals including lopinavir and ritonavir. The use of this drug in the coronavirus infection has indicated a significant improvement in chest complications and decreasing the viral load [54]. The mechanistic details reveal that the favipiravir drug blocks the replication of ribonucleic acid (RNA) viruses and hence, good results are expected against the COVID-19 infection while administering this drug [55].

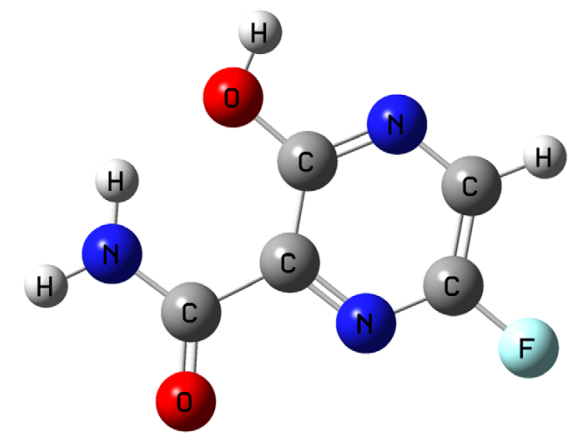

(a)

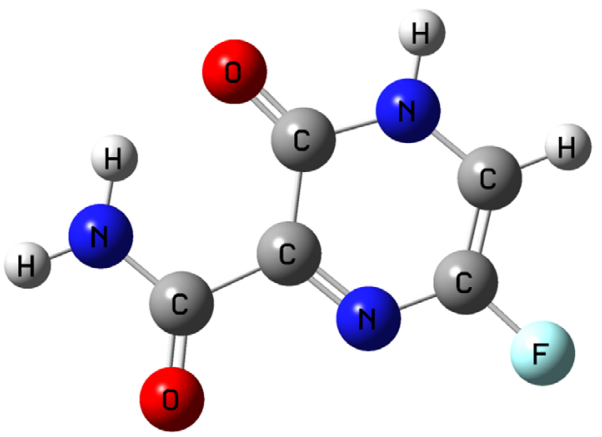

(b)

Figure 3. 3D structural representation of (a) hydroxyl favipiravir and (b) oxo favipiravir (Drawn in GaussView5.0) 


\subsection{Remdesivir}

Remdesivir is another RNA polymerase inhibitor with high power of antiviral activity and hence able to act against coronavirus. In recent randomized trials conducted to find the effective dosage of this drug against nCOVID patients, the results have shown good effects in the dosage uptake of 100-200 mg daily, while a 5-10 mg/day dose showed no significant difference [56]. Similar observations in a placebo-controlled trial of intravenous remdesivir in adults with confirmed infection were given $200 \mathrm{mg}$ on day 1 , then $100 \mathrm{mg}$ daily for up to 9 or 10 days. This administration has shown shortening the recovery time [57]. Some of the side effects expected from this drug urge the scientific community to seek for safety and efficacy of such drugs [58]. Some assumptions like drug combination and intervention of Chinese herbal medicines along such treatment strategies have received considerable attention to curtail the physiological abnormalities like cytokine storm - a major cause of deaths [59, 60]. Figure 4 shows the 3D structure of this drug.

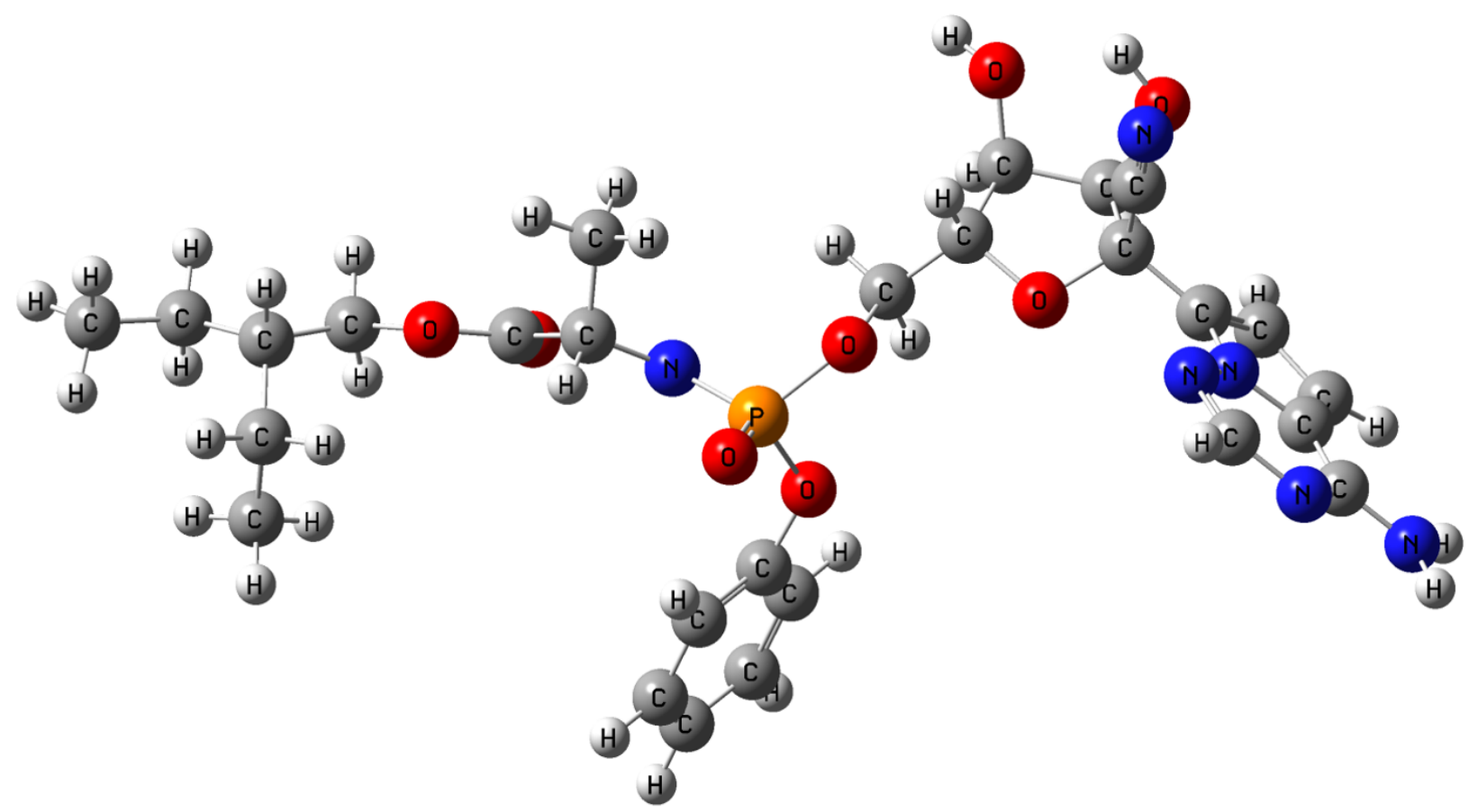

Figure 4. 3D structure of remdesivir (Drawn in GaussView5.0)

\subsection{Lopinavir and ritonavir}

Because of the emergency use of antiviral drugs for COVID-19 treatment, the benefit-risk profile for lopinavirritonavir (Figure 5 and Figure 6) is still underway to further study its efficacy and effectiveness [61]. The repositioning of these drugs from their use for the treatment of SARS-CoV-1 to SARS-CoV-2 has been found beneficial in emergency treatment despite lower antiviral efficacy as compared with arbidol [62]. Hence, drugs like lopinavir and ritonavir should be further investigated to avail permission from the US Food and Drug Administration (FDA) for safety concerns [63, 64]. In due course, some trials for such therapies have got scientific concerns involving six trials for lopinavir-ritonavir and several other trials for other drugs [65]. The mechanistic details of lopinavir-ritonavir for SARS-CoV-2 treatment indicates binding property with ACE2 and also potent protease inhibition to inhibit replication of the viral RNA [66]. 


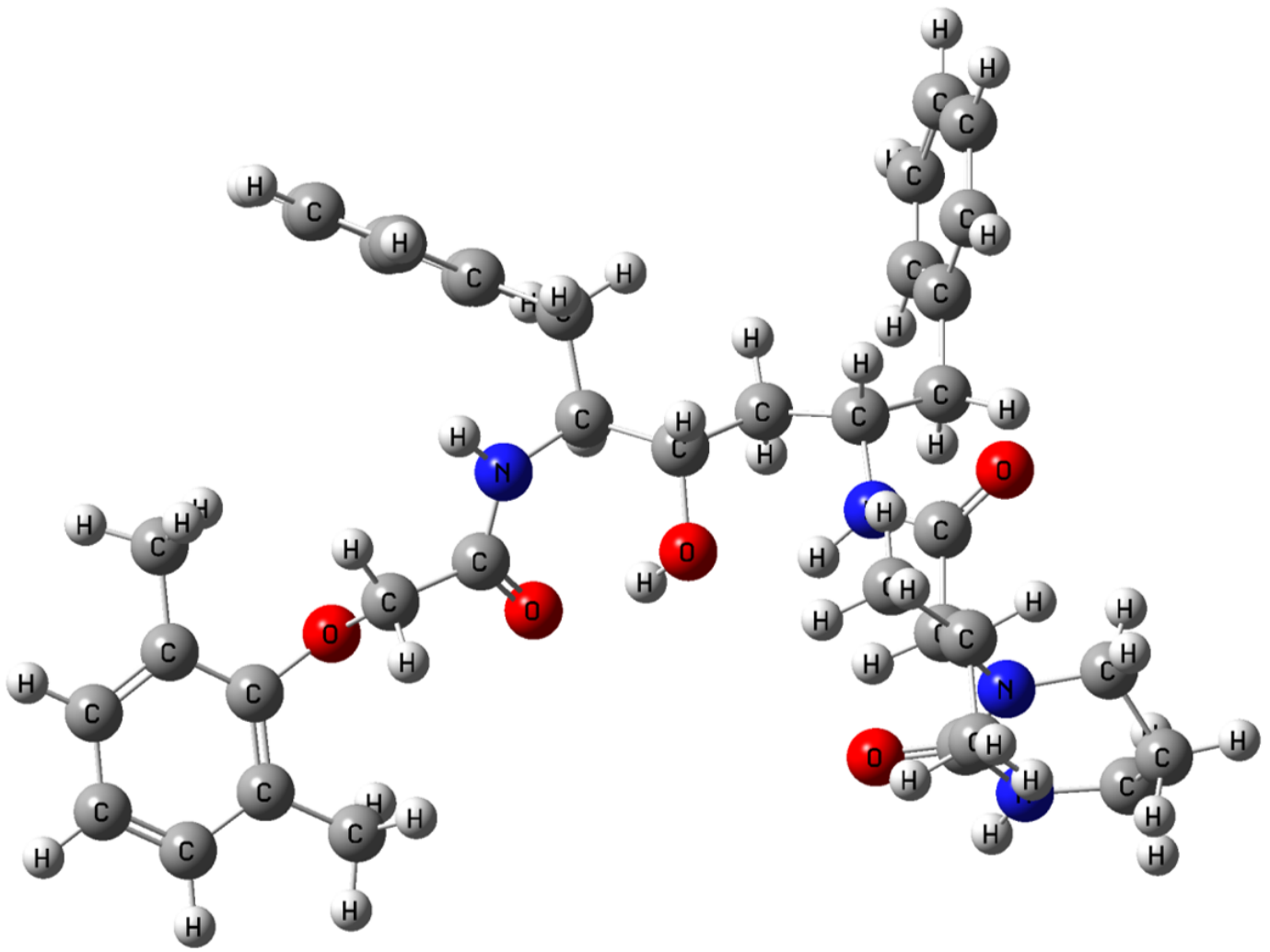

Figure 5. 3D structure of lopinavir (Drawn in GaussView5.0)

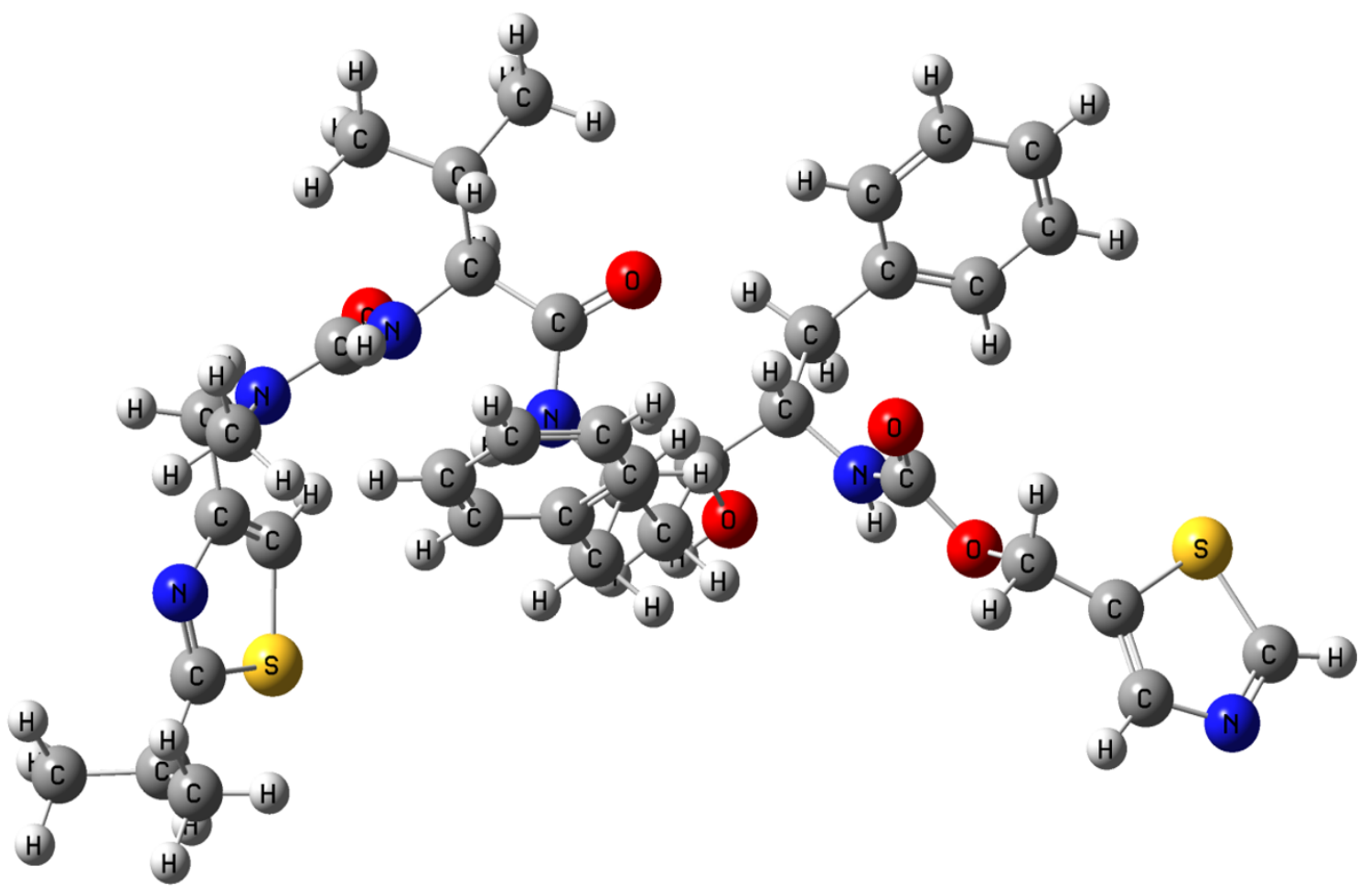

Figure 6. 3D structure of ritonavir (Drawn in GaussView5.0) 


\section{Other therapeutic options}

Therapy, in general, may be defined as the remediation attempt of any health-associated problem by following the diagnostic ways. In the usual medical sense, the term signifies treatment. In addition to several drug therapies (antiviral repurposing) as discussed above, some of the commonly known therapies applicable for COVID-19 treatment have been discussed below.

\subsection{Ozone therapy}

The respiratory system is mainly involved in the gaseous exchange phenomenon of normal physiological functions. The virus that causes respiratory issues can produce symptoms including cold, pneumonia, fever, etc. At the same time, the immune response in the form of inflammation is the main symptom behavior of virus invasion. The use of new therapies like ozone therapy (OT) represents one of the best options to stop inflammation [67]. Earlier studies involving OT have shown satisfactory results for the treatment of gastrointestinal inflammations despite the unknown mechanism behind this treatment option [68]. However, based on different experimental studies it has been revealed that ozone $\left(\mathrm{O}_{3}\right)$ enhances antioxidant activity and hence, retards the mucosal damage of the intestine [69]. In medicine, OT involves the use of a combination of $\mathrm{O}_{3}$ and oxygen $\left(\mathrm{O}_{2}\right)$, producing a series of effects over pathology state and medical practices. By this technique, tissues can be oxygenated in a better way and decrease the lung inflammation to regulate the respective immune response [70]. $\mathrm{O}_{3}$ is a strong oxidizing agent and can thus be used to disinfect viral infection [71]. Ozonation could result in a decrease in viral load [72].

In special reference to COVID-19, four significant properties have been linked with OT. These include the effects of $\mathrm{O}_{3}$ in improving gas exchange, reducing inflammation, modulating antioxidative behavior, and inactivating the virus. In previous reports, the therapy has shown good results against the Ebola virus [73]. The anti-inflammatory response of this therapy could be assumed as the main reason for the use in nCOVID patients. OT has been reported to protect ischemia-reperfusion injury (IRI) and therefore should be investigated in relevance to COVID-19 [74]. Several studies related to the mechanism of action of OT, the respective physiological impact, and cytoprotective roles are supportive to suggest OT as a therapeutic option for the treatment of COVID-19 patients [75]. Also, some experimental studies invoking the in vivo tests of coronavirus infected patients using OT have found this therapy beneficial in improving lung capacity, normalizing the redox potential, and also the activation of heme oxygenase (HO-1) [76]. Similar observations of the beneficial role of OT have been reported in recent case reports where $\mathrm{O}_{3}$ has been found a potent anti-inflammatory tool [77]. Though some health supplements are also necessary addition for the COVID-19 treatment [78], the powerful antioxidant potential of $\mathrm{O}_{3}$ has been suggested the key factor to increase $\mathrm{O}_{2}$ in the blood and other tissues, showing profound implications in glycolysis, Krebs cycle, subcellular role in the mitochondrial antioxidative pathway and anti-inflammatory response in cytokines [79]. Therefore, in a special focus on using OT for SARS-CoV-2 treatment may also be understood by looking at the cellular interaction of $\mathrm{O}_{3}$ with the coronavirus. Many viruses need a reduced form of sulfhydryl functionality for cellular fusion, but these functional groups are vulnerable to oxidation [80], and hence OT may disinfect the virus in this way $[81,82]$.

\subsection{Plasma therapy}

During emergency times in the COVID-19 pandemic, this type of therapeutics played a prominent role in recovering the suffered patients. Even intensive care unit (ICU) admitted patients responded well to plasma exchange therapy [83]. Plasma therapy (PT) involves the use of convalescent plasma of recovered patients for the treatment of newly infected patients [84]. Earlier reports of using the same therapy in treating influenza A virus subtype H1N1 infection indicate successful eradication of the cytokine storm and rectifying the lung functioning, and therefore the same expectation was felt for the emergency treatment of COVID-19 [85]. The administration of PT has been in practice since the 1900s for the treatment of emerging infections and the efficacy of such therapies has been found based on the associated polyclonal neutralizing antibodies [86]. Several PT-administered successful stories got published in this context. In one such report, one COVID-19 patient recovered completely after giving two successive convalescent PTs [87]. Thus, passive immunization plays a key role in treating such viral infections [88].

In order to find the role of blood components in PT, some studies performed total blood cell analysis of PT-treated 
COVID-19 patients. A significant difference was noticed in all the blood components [89]. PT hence proved effective in saving precious lives when an emergency was declared in the COVID-19 pandemic [90]. Many studies related to the effect of the therapy report that the planned therapy dose ranges from 200-800 $\mathrm{mL}$ [91]. This therapeutic option appeared fascinated for the treatment of COVID-19, but the questions arising for the determination of real mechanisms and efficacy are still on the screen [92].

\subsection{Nitric oxide therapy}

Viral invasion in the human body creates the overproduction of free radicals, like in other pathogenic states including cancer, heart, diabetes, hypertension, etc [93]. The same happens in the COVID-19 infectious state [94]. These reactive species affect physiological homeostasis [95]. Among several such chemical species, nitrogen reactive free radicals have a profound role in cytokine regulation immunomodulation and various cell signaling pathways [96]. In the case of the imbalance of oxidants, harmful effects arise and oxidation stress gets created [95, 96]. Oxidative stress has been the main cause of COVID-19 deaths especially comorbid deaths [97, 98]. Therefore, the treatment of coronavirus infectious state in addition to other options including nitric oxide (NO) therapy has been suggested as a good option to functionalize the affected lungs, decrease the viral load, control cytokine storm, and kill the virus. R-107 and COViNOX are the two familiar NO-based prodrugs for COVID-19 treatment. Many scientific reports insist the use of NO-therapy and the mechanism of action, especially on nCOVID treatment is under vigorous investigation [22]. In addition to the above, the potential of $\mathrm{NO}$ to boost immunity might prove worthy in formulating the final specific medicine and vaccine for nCOVID [99]. As far as the NO-therapy-based mechanism is concerned, both the S protein fusion and halting of RNA replication have been proposed, as shown in Figure 7.

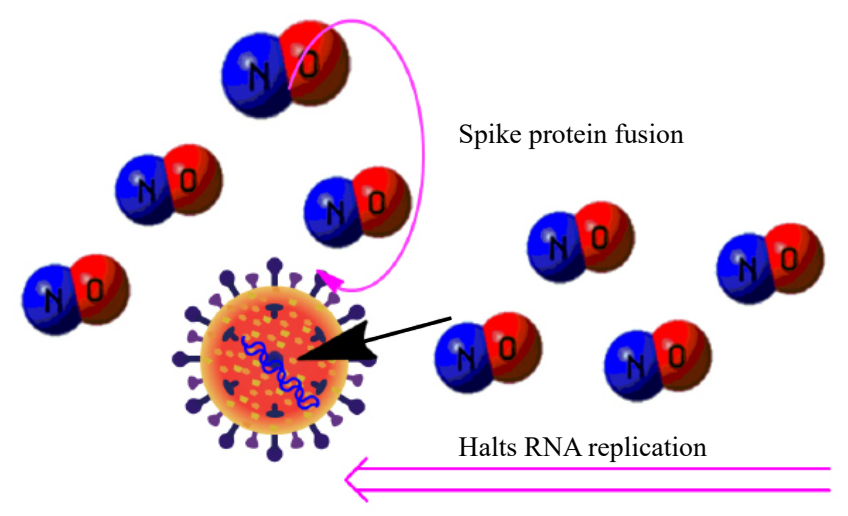

Figure 7. NO-mediated anti-coronavirus activity [22: p.13]

\subsection{Aromatherapy}

The use of essential oils in the form of extracts obtained from herbal plants, flowers, etc., as a treatment for several diseases has been in practice for many years ago in many countries including India, Egypt, and especially in Europe. The term aromatherapy (AT) itself reflects its meaning concerning aromatic products or plants [100]. This has been widely accepted that essential oils are potent anti-inflammatory, bronchodilatory, immunomodulatory, and antiviral candidates. Therefore, it is logical to have a similar potential for SARS-CoV-2. Also, due to the presence of active phytochemicals in essential oils, it helps to reduce the viral load by showing anti-coronaviral activity in multiple stages. The primary positive impact on the host's respiratory tract suggests that the AT option can effectively treat COVID-19 infection [101]. 


\subsection{Photodynamic therapy}

Photodynamic therapy (PDT) mainly involves a light-driven modern technique that uses photosensitizer as an excitation source for the formation of reactive species. Light-based therapy can also be suggested as another option for the treatment of SARS-CoV-2. The therapy is especially applicable for cancer treatment and killing microbes from surfaces, air, wastewater, air, etc [102]. Such a disinfecting approach can be suggested for COVID-19 treatment as well.

\section{Role of molecular simulation in speculating the COVID-19 treatment}

In the main SARS-CoV-2 period, experimental investigations were not so easy to deal with the deadly virus. Hence, the direct practical examinations were mostly replaced by computational studies to speculate on the structureactivity relationship between so many natural and synthetic compounds and reported coronaviruses. Despite social distancing and administrative lockdowns, theoretical chemistry put forth potential views to find the efficacies of drugs repurposed for COVID-19 treatment. This section has been highlighted under two heads viz., density functional theory (DFT) approach and molecular docking.

\subsection{Density functionalized status of COVID-19 drugs}

DFT is the prominent theoretical tool in elucidating quantum chemical-based molecular descriptors. This theory is applicable almost in every field of research. Presently, in the COVID-19 pandemic times, the repurposed drugs have generated a ray of hope for the treatment. However, it looks prime concern to find the drug efficacy of these candidates based on theoretical calculations. DFT-based speculation has recently suggested silver-carbene complexes as potential candidates to prevent SARS-CoV-2 viral infection [103] and the probable mechanism may be sought from the determination of non-covalent interactions with main proteases [104]. Among several reactive descriptors useful for such studies, DFT-based estimation to find parameters related to thermal analysis, dipole tensors, and coulombic potentiality has a profound effect to elaborate the anti-COVID-19 drug properties [105]. Such efforts have yielded approaches to design COVID-19 treatment lead compounds [106]. Similar promising results have been reported and several amino acids have been declared as effective anti-COVID-19 candidates [107]. The density functional aspects reported for remdesivir-repurposed anti-COVID-19 drug serve as fine tools to understand its inhibiting potential against SARS-CoV-2 genetic polymerase [108]. Similar simulation studies of 2-[N-(carboxymethyl)anilino] acetic acid (PIDAA) have been reported for the evaluation of its reactive properties in finding its application for COVID-19 treatment [109]. In addition to the reactive descriptors, the computational results confined to binding energies using DFT have been used to find the drug binding affinity of several influenza medicines, to reach a better predictive approach for SARSCoV-2 treatment [110, 111]. Not only enzyme interaction can be sought from DFT, but also the drug adsorption studies which help design drug potencies [112]. The combination of the DFT method with molecular docking represents a fine approach for more sound speculation of drug designing [104, 113]. The studies of molecular interaction with enzyme active sites should, first of all, involve geometry optimization using DFT. Therefore, to go for molecular docking studies to reveal COVID-19 treatment, the initial DFT-based optimization is a necessary step. For example, an exhaustive study conducted by Hagar et al. first studied four main compounds: (i) favipiravir, (ii) amodiaquine, (iii) 2'-fluoro-2'deoxycytidine, and (iv) ribavirin theoretically at DFT level, and followed by the docking revealing DFT parameters (Table 1) could share with the different extent to significantly affect the binding affinity of these drugs to the active protein sites [105]. The parameters given in Table 1 are calculated by solving the following equations:

$$
\begin{gathered}
\Delta_{\text {LUMо-номо }}=\mathrm{E}_{\text {LUMO }}-\mathrm{E}_{\text {Номо }} \\
\chi=\frac{-\left(\mathrm{E}_{\text {номо }}+\mathrm{E}_{\text {LUMO }}\right)}{2}=\frac{(\mathrm{I}+\mathrm{A})}{2}
\end{gathered}
$$




$$
\begin{gathered}
-\mathrm{E}_{\text {номо }}=\mathrm{I} \\
-\mathrm{E}_{\text {LUMO }}=\mathrm{A} \\
\eta=\frac{\left(\mathrm{E}_{\text {LUMO }}-\mathrm{E}_{\text {HOMO }}\right)}{2} \\
\omega=\frac{\mu^{2}}{2 \eta} \\
\delta=\frac{1}{\eta}
\end{gathered}
$$

\begin{tabular}{|c|c|c|c|c|c|c|c|c|c|}
\hline Drug & $\mathrm{E}_{\text {номо }}$ & $\mathrm{E}_{\text {LUMO }}$ & $\Delta \mathrm{E}$ & $\chi$ & $\eta$ & $\delta$ & $\omega$ & I & A \\
\hline $\mathrm{i}$ & -7.61 & -5.47 & 2.14 & 2.06 & 1.07 & 0.94 & 2.27 & 7.61 & 5.47 \\
\hline ii & -5.65 & -1.65 & 4.00 & 3.70 & 2.00 & 0.50 & 13.69 & 5.65 & 1.65 \\
\hline iii & -6.34 & -1.05 & 5.28 & 3.65 & 2.64 & 0.38 & 17.59 & 6.34 & 1.05 \\
\hline iv & -7.22 & -1.68 & 5.54 & 3.04 & 2.77 & 0.36 & 12.80 & 7.22 & 1.68 \\
\hline
\end{tabular}

Table 1. Calculated electronegativity $(\chi)$, global hardness $(\eta)$, softness $(\delta)$, global electrophilicity index $(\omega)$, ionization potential $(I)$ and the electron affinity (A) in eV of investigated compounds i-iv [105: p.4]

\subsection{Molecular docking as the main theoretical approach in finding $n$ COVID treatment}

The uncontrolled number of deaths caused by COVID-19 and its rapid transmission resulted in the proclamation of WHO to declare this disease as pandemic [114]. The entire scientific world started working on this new infection. Meanwhile, molecular simulation studies in the form of computational docking served as the best tool to predict the structure-activity relations of previously used antiviral drugs [115]. By the intervention of such studies, lopinavir, ritonavir, oseltamivir, ribavirin, and many other drug candidates began to be repurposed for the treatment of SARSCoV-2 disease [116, 117]. Computational chemists began to interrogate other types of compounds including synthetic as well as natural to depict an effective nCOVID drug [118-121]. For instance, among the drugs that are being tested in clinical trials for COVID-19, danoprevir and darunavir have the highest binding affinity to the target main protease of SARS-CoV-2. Saquinavir and beclabuvir were identified as the best novel candidates for COVID-19 therapy by using virtual screening of drugs approved for other clinical indications.

The computationally evolved protein-ligand interactions to predict the effectiveness of several repositioned drugs against SARS-CoV-2 have been shown to possess a potential inhibitory action [122]. For hydroxychloroquine, molecular docking and simulation evaluation also shows well fascinating docking score against the SARS-CoV-2 proteases, revealing the structural framework of the key residues [123]. Similar studies upon some of the drugs approved by the FDA that have been used in past epidemics indicate that out of ten selected drugs, brincidofovir is considered the highest antiviral drug for the treatment of COVID-19 [124]. In a similar sense, natural products like piperine, capsaicin, piperine, and curcumin have been shown to have the capability of effective interactions with the viral proteases [125]. Therefore, the main computational approach in the form of docking analysis proved helpful at the times when only lockdown and physical distancing were felt necessary to curb the pandemic.

\section{Development COVID-19 vaccine: final destination before a specific medication}

In medical terminology, a vaccine may be defined as a source of active acquired immunity prepared under 
biological requirements for a specific type of infection. The composition of a vaccine resembles typically that of a microorganism that causes the infection and the selection of material is done very carefully so that microbial deactivated or in killed form, or any other related surface proteins are allowed to be the part of the vaccine. As of now, the world community is carrying out a vaccination drive for COVID-19. At the times when there was no human vaccine available in the market, several strategies to treat and curb this dreadful infectious disease were only the source of protection. The combinatory results of experimental and theoretical scientists have led to a successful launch of a final trial of the vaccination against COVID-19 [126].

Coronaviruses as discussed have positively-stranded RNA with its genetic material packed within the nucleocapsid $(\mathrm{N})$ protein and covered by specific proteins viz., membrane (M) protein, envelope (E) protein, and the S protein [127]. Earlier, in the development of a vaccine, different SP were targeted, most of these studies ceased after the SARS and Middle East respiratory syndrome (MERS) outbreaks. But with the recent pandemic outbreak, it was felt urgent to resume the work on this vaccine research. As a result, on March 16, 2020, the first series of trials to test these $\mathrm{S}$ protein-targeted coronavirus vaccines (messenger RNA based) in humans began on a preferential basis (ClinicalTrials. gov Identifier: NCT04283461) (Table 2) [128].

Table 2. Reported SARS-CoV, Middle East respiratory syndrome coronavirus (MERS-CoV), SARS-CoV-2 vaccine clinical trials [128-137]

\begin{tabular}{|c|c|c|c|c|c|}
\hline Virus & Location & Phase & Year & Identifier & Vaccine Type \\
\hline SARS-CoV & United States & I & 2004 & NCT00099463 & Recombinant DNA vaccine (S protein) \\
\hline SARS-CoV & United States & I & 2007 & NCT00533741 & Whole virus vaccine \\
\hline SARS-CoV & United States & I & 2011 & NCT01376765 & Recombinant protein vaccine (S protein) \\
\hline MERS & United Kingdom & I & 2018 & NCT03399578 & Vector vaccine (S protein) \\
\hline MERS & Germany & I & 2018 & NCT03615911 & Vector vaccine (S protein) \\
\hline MERS & Saudi Arabia & I & 2019 & NCT04170829 & Vector vaccine (S protein) \\
\hline MERS & Germany, Netherland & I & 2019 & NCT04119440 & Vector vaccine (S protein) \\
\hline MERS & Russia & I, II & 2019 & NCT04128059 & Vector vaccine (protein not specified) \\
\hline MERS & Russia & I, II & 2019 & NCT04130594 & Vector vaccine (protein not specified) \\
\hline SARS-CoV-2 & United States & I & 2020 & NCT04283461 & mRNA-based vaccine (S protein) \\
\hline
\end{tabular}

As $\mathrm{S}$ protein is the main crucial mediator in virus entry, and hence in the SARS vaccine development, this fulllength protein (with S1 subunit: main receptor) have been sought as the main antigens for the vaccine development for referred. This is mainly due to its significance in neutralizing antibodies that prevent host cell infection. Despite all this, studies have shown that among viral proteins, $\mathrm{S}$ protein targeted vaccination is not fully protective because of some safety concerns $[138,139]$. Meanwhile, significant research was conducted to generate efforts for developing more efficacious COVID-19 vaccines [140]. For instance, reverse vaccinology (RV) in this context has put promising candidates for vaccine by employing bioinformatic analysis over the pathogenic genome. RV appears to have successfully applied the same to vaccine discovery, including Group B meningococcus that led to licensing Bexsero as a vaccine [141].

The Russian Direct Investment Fund (RDIF), since the start of the COVID-19 pandemic, has played a key role in fighting the virus in Russia and played the main role in bringing up SPUTNIK V as a vaccine for COVID-19. Recently, Moderna's CEO also announced that the final form of its vaccine has 94 percent efficacy. By the 18th of December 2020, the Moderna Vaccine was granted FDA approval. Beijing Institute of Biological Products, Sinopharm is also testing its vaccine almost in the final phase. Previously, AstraZeneca, also in the final phase of work, reported that their FDAauthorized vaccine produces a strong immune response in a clinical trial involving people over the age of 70 [142]. Meanwhile, Pfizer and Covaxin are also the famous COVID-19 vaccines. Many other vaccines have entered into the general vaccination stage. Hence thanks to the health scientists.

\section{Concluding remarks and future directions}

Before coming to the conclusions and suggestions extracted from this literature survey, it looks good to mention here a quotation displayed on the WHO website (12th January 2021) that reads "With a fast-moving pandemic, no one 
is safe, unless everyone is safe". This work aimed to present a sequential form of literature confined to the initial stage of the COVID-19 pandemic, followed by diagnosis and drug repurposing, and finally good news of having reached a level of vaccination as the near end to the 2020 apocalyptic time. In the several approaches brought to light through this survey, it is to mention here that viral strains are never stagnant, they keep on changing their functionality concerning the environment. Hence, scientists should be ready to encounter any type of pandemic like COVID-19 in the future. Very recently the second type of coronaviral strain has regenerated the COVID-19 fear-like situation. Several countries have restarted lockdown strategies and physical distancing to prevent the people from this second coronavirus strain, which has $70 \%$ more communicability as compared to the previous form. Therefore, having reached the vaccination stage and bringing COVID-19 to control doesn't mean that we are safe. Some of the directions need to ponder as listed below:

i. Going through drug repurposing and virtual screening results, it is evident that such research fields should be boosted to get more evolved in terms of machine learning.

ii. Non-clinical spectroscopic viral analysis should be made as advanced as possible so that RT-PCR's less reliability gets replaced by reliable testing.

iii. As it is a fact that protection from any infectious disease cannot be demonstrated for any specific available right, therefore further development is required to bring forth a highly efficacious vaccine.

iv. Antibodies rendered towards S protein may offer some protective way out against SARS. On the other hand, it is acceptable that such high antibody titers are unable to defend the SARS-CoV challenge.

v. In case of the outbreak of another epidemic or pandemic, research and funding for the development of vaccines must be a priority.

vi. SARS-CoV pandemic caused lakhs of deaths, and it is expected this viral infection may now jump to animals, suggesting that another pandemic may occur.

vii. The world is still waiting for a $100 \%$ efficient vaccine. Let mucosal immunization, T-cell immunity, and attenuated SARS-CoV vaccines be the new future directions in this type of research.

\section{Conflict of interest statement}

There is no conflict of interest for this study.

\section{References}

[1] Chen M, Li M, Hao Y, Liu Z, Hu L, Wang L. The introduction of population migration to SEIAR for COVID-19 epidemic modeling with an efficient intervention strategy. Information Fusion. 2020; 64: 252-258. Available from: doi:10.1016/j.inffus.2020.08.002.

[2] Shereen MA, Khan S, Kazmi A, Bashir N, Siddique R. COVID-19 infection: origin, transmission, and characteristics of human coronaviruses. Journal of Advanced Research. 2020; 24: 91-98. Available from: doi:10.1016/j.jare.2020.03.005.

[3] Kang L, Ma S, Chen M, Yang J, Wang Y, Li R, et al. Impact on mental health and perceptions of psychological care among medical and nursing staff in Wuhan during the 2019 novel coronavirus disease outbreak: a cross-sectional study. Brain, Behavior, and Immunity. 2020; 87: 11-17. Available from: doi:10.1016/j.bbi.2020.03.028.

[4] Russell B, Moss C, Rigg A, Van Hemelrijck M. COVID-19 and treatment with NSAIDs and corticosteroids: should we be limiting their use in the clinical setting? ecancermedicalscience. 2020; 14: 1023. Available from: doi:10.3332/ecancer.2020.1023.

[5] Zhou F, Yu T, Du R, Fan G, Liu Y, Liu Z, et al. Clinical course and risk factors for mortality of adult inpatients with COVID-19 in Wuhan, China: a retrospective cohort study. The Lancet. 2020; 395(10229): 1054-1062. Available from: doi:10.1016/S0140-6736(20)30566-3.

[6] Zhou Y, Wang F, Tang J, Nussinov R, Cheng F. Artificial intelligence in COVID-19 drug repurposing. The Lancet Digital Health. 2020; 2(12): e667-e676. Available from: doi:10.1016/S2589-7500(20)30192-8.

[7] Gao J, Tian Z, Yang X. Breakthrough: chloroquine phosphate has shown apparent efficacy in treatment of 
COVID-19 associated pneumonia in clinical studies. 2020; 14(1): 72-73. BioScience Trends. Available from: doi:10.5582/bst.2020.01047.

[8] Savarino A, Boelaert JR, Cassone A, Majori G, Cauda R. Effects of chloroquine on viral infections: an old drug against today's diseases? The Lancet Infectious Diseases. 2003; 3(11): 722-727. Available from: doi:10.1016/ S1473-3099(03)00806-5.

[9] Yan Y, Zou Z, Sun Y, Li X, Xu K-F, Wei Y, et al. Anti-malaria drug chloroquine is highly effective in treating avian influenza A H5N1 virus infection in an animal model. Cell Research. 2013; 23(2): 300-302. Available from: doi:10.1038/cr.2012.165.

[10] Chu CM, Cheng VCC, Hung IFN, Wong MML, Chan KH, Chan KS, et al. Role of lopinavir/ritonavir in the treatment of SARS: initial virological and clinical findings. Thorax. 2004; 59(3): 252-256. Available from: doi:10.1136/thorax.2003.012658.

[11] Keyaerts E, Vijgen L, Chen L, Maes P, Hedenstierna G, Van Ranst M. Inhibition of SARS-coronavirus infection in vitro by S-nitroso-N-acetylpenicillamine, a nitric oxide donor compound. International Journal of Infectious Diseases. 2004; 8(4): 223-226. Available from: doi:10.1016/j.ijid.2004.04.012.

[12] Fakhr BS, Wiegand SB, Pinciroli R, Gianni S, Morais CCA, Ikeda T, et al. High concentrations of nitric oxide inhalation therapy in pregnant patients with severe coronavirus disease 2019 (COVID-19). Obstetrics \& Gynecology. 2020; 136(6): 1109-1113. Available from: doi:10.1097/AOG.0000000000004128.

[13] Akaike T, Maeda H. Nitric oxide and virus infection. Immunology. 2000; 101(3): 300-308. Available from: doi:10.1046/j.1365-2567.2000.00142.x.

[14] Barrington KJ, Finer N, Pennaforte T, Altit G. Nitric oxide for respiratory failure in infants born at or near term. Cochrane Database of Systematic Reviews. 2017; 2017(1): CD000399. Available from: doi:10.1002/14651858. CD000399.pub3.

[15] Isihak FA, Hamad MA, Mustafa NG. COVID-19: an updated review. Russian Journal of Infection and Immunity. 2020; 10(2): 247-258. Available from: doi:10.15789/2220-7619-CAU-1443.

[16] Chan JF-W, Kok K-H, Zhu Z, Chu H, To KK-W, Yuan S, et al. Genomic characterization of the 2019 novel humanpathogenic coronavirus isolated from a patient with atypical pneumonia after visiting Wuhan. Emerging Microbes \& Infections. 2020; 9(1): 221-236. Available from: doi:10.1080/22221751.2020.1719902.

[17] Tang X, Wu C, Li X, Song Y, Yao X, Wu X, et al. On the origin and continuing evolution of SARS-CoV-2. National Science Review. 2020; 7(6): 1012-1023. Available from: doi:10.1093/nsr/nwaa036.

[18] Song W, Gui M, Wang X, Xiang Y. Cryo-EM structure of the SARS coronavirus spike glycoprotein in complex with its host cell receptor ACE2. PLOS Pathogens. 2018; 14(8): e1007236. Available from: doi:10.1371/journal. ppat.1007236.

[19] Zhou P, Yang X-L, Wang X-G, Hu B, Zhang L, Zhang W, et al. A pneumonia outbreak associated with a new coronavirus of probable bat origin. Nature. 2020; 579: 270-273. Available from: doi:10.1038/s41586-020-2012-7.

[20] Kahn JS, McIntosh K. History and recent advances in coronavirus discovery. Pediatric Infectious Disease Journal. 2005; 24(11): S223-S227. Available from: doi:10.1097/01.inf.0000188166.17324.60.

[21] Andersen KG, Rambaut A, Lipkin WI, Holmes EC, Garry RF. The proximal origin of SARS-CoV-2. Nature Medicine. 2020; 26(4): 450-452. Available from: doi:10.1038/s41591-020-0820-9.

[22] Mir JM, Maurya RC. Nitric oxide as a therapeutic option for COVID-19 treatment: a concise perspective. New Journal of Chemistry. 2021; 45(4): 1774-1784. Available from: doi:10.1039/D0NJ03823G.

[23] Mir JM, Khan MW, Shalla AH, Maurya RC. A nonclinical spectroscopic approach for diagnosing COVID-19: a concise perspective. Journal of Applied Spectroscopy. 2021; 88(4): 765-771. Available from: doi:10.1007/s10812021-01238-9.

[24] Khan RS, Rehman IU. Spectroscopy as a tool for detection and monitoring of Coronavirus (COVID-19). Expert Review of Molecular Diagnostics. 2020; 20(7): 647-649. Available from: doi:10.1080/14737159.2020.1766968.

[25] Wu K, Saha R, Su D, Krishna VD, Liu J, Cheeran MC-J, et al. Magnetic immunoassays: a review of virus and pathogen detection before and amidst the coronavirus disease-19 (COVID-19). Arxiv [Preprint] 2020. Available from: https://arxiv.org/abs/2007.04809 [Accessed 15th December 2021].

[26] Mahapatra S, Chandra P. Clinically practiced and commercially viable nanobio engineered analytical methods for COVID-19 diagnosis. Biosensors and Bioelectronics. 2020; 165: 112361. Available from: doi:10.1016/ 
j.bios.2020.112361.

[27] Orsburn BC, Jenkins C, Miller SM, Neely BA, Bumpus NN. In silico approach toward the identification of unique peptides from viral protein infection: application to COVID-19. Biorxiv [Preprint] 2020. Available from: doi:10.1101/2020.03.08.980383.

[28] Carvalho LFDCES, Nogueira MS. Optical techniques for fast screening - towards prevention of the coronavirus COVID-19 outbreak. Photodiagnosis and Photodynamic Therapy. 2020; 30: 101765. Available from: doi:10.1016/ j.pdpdt.2020.101765.

[29] Seo G, Lee G, Kim MJ, Baek S-H, Choi M, Ku KB, et al. Rapid detection of COVID-19 causative virus (SARSCoV-2) in human nasopharyngeal swab specimens using field-effect transistor-based biosensor. ACS Nano. 2020; 14(4): 5135-5142. Available from: doi:10.1021/acsnano.0c02823.

[30] Mahmud I, Garrett TJ. Mass spectrometry techniques in emerging pathogens studies: COVID-19 perspectives. Journal of the American Society for Mass Spectrometry. 2020; 31(10): 2013-2024. Available from: doi:10.1021/ jasms.0c00238.

[31] Sheridan C. Coronavirus and the race to distribute reliable diagnostics. Nature Biotechnology. 2020; 38(4): 382384. Available from: doi:10.1038/d41587-020-00002-2.

[32] Taha B, Arsad N, Al Mashhadany Y. An analysis review, detection coronavirus disease 2019 (COVID-19) based on biosensor application. Biomedical \& Chemical Engineering [Preprint] 2020. Available from: doi:10.20944/ preprints202008.0597.v1.

[33] Whetton AD, Preston GW, Abubeker S, Geifman N. Proteomics and informatics for understanding phases and identifying biomarkers in COVID-19 disease. Journal of Proteome Research. 2020; 19(11): 4219-4232. Available from: doi:10.1021/acs.jproteome.0c00326.

[34] Singh R, Su P, Kimerling L, Agarwal A, Anthony BW. Detection of bio-aerosols and COVID-19 equivalent particles via on-chip mid infrared photonic spectroscopy. Arxiv [Preprint] 2020. Available from: http://arxiv.org/ abs/1806.06910v2 [Accessed 15th December 2021].

[35] Chandra P. Miniaturized label-free smartphone assisted electrochemical sensing approach for personalized COVID-19 diagnosis. Sensors International. 2020; 1: 100019. Available from: doi:10.1016/j.sintl.2020.100019.

[36] Nogueira MS. Optical theranostics and treatment dosimetry for COVID-19 lung complications: towards increasing the survival rate of vulnerable populations. Photodiagnosis and Photodynamic Therapy. 2020; 31: 101892. Available from: doi:10.1016/j.pdpdt.2020.101892.

[37] Rabiee N, Bagherzadeh M, Ghasemi A, Zare H, Ahmadi S, Fatahi Y, et al. Point-of-use rapid detection of SARSCoV-2: nanotechnology-enabled solutions for the COVID-19 pandemic. International Journal of Molecular Sciences. 2020; 21(14): 5126. Available from: doi:10.3390/ijms21145126.

[38] Nogueira MS. Biophotonics for pandemic control: large-area infection monitoring and microbial inactivation of COVID-19. Photodiagnosis and Photodynamic Therapy. 2020; 31: 101823. Available from: doi:10.1016/ j.pdpdt.2020.101823.

[39] Li X, Wang Y, Agostinis P, Rabson A, Melino G, Carafoli E, et al. Is hydroxychloroquine beneficial for COVID-19 patients? Cell Death \& Disease. 2020; 11(7): 512. Available from: doi:10.1038/s41419-020-2721-8.

[40] Chen Z, Hu J, Zhang Z, Jiang S, Han S, Yan D, et al. Efficacy of hydroxychloroquine in patients with COVID-19: results of a randomized clinical trial. Medrxiv [Preprint] 2020. Available from: doi:10.1101/2020.03.22.20040758.

[41] Pal A, Pawar A, Goswami K, Sharma P, Prasad R. Hydroxychloroquine and COVID-19: a cellular and molecular biology based update. Indian Journal of Clinical Biochemistry. 2020; 35(3): 274-284. Available from: doi:10.1007/ s12291-020-00900-x.

[42] Yu B, Li C, Chen P, Zhou N, Wang L, Li J, et al. Low dose of hydroxychloroquine reduces fatality of critically ill patients with COVID-19. Science China Life Sciences. 2020; 63(10): 1515-1521. Available from: doi:10.1007/ s11427-020-1732-2.

[43] Carlucci PM, Ahuja T, Petrilli C, Rajagopalan H, Jones S, Rahimian J. Hydroxychloroquine and azithromycin plus zinc vs hydroxychloroquine and azithromycin alone: outcomes in hospitalized COVID-19 patients. Medrxiv [Preprint] 2020. Available from: doi:10.1101/2020.05.02.20080036.

[44] Khuroo MS. Chloroquine and hydroxychloroquine in coronavirus disease 2019 (COVID-19). Facts, fiction and the hype: a critical appraisal. International Journal of Antimicrobial Agents. 2020; 56(3): 106101. Available from: 
doi:10.1016/j.ijantimicag.2020.106101.

[45] Batra U, Sharma M, Redhu P. Chloroquine and hydroxychloroquine: clutching at straws in the time of COVID-19? Cancer Research, Statistics, and Treatment. 2020; 3(5): 3-6. Available from: doi:10.4103/CRST.CRST_147_20.

[46] Choudhary R, Sharma AK. Potential use of hydroxychloroquine, ivermectin and azithromycin drugs in fighting COVID-19: trends, scope and relevance. New Microbes and New Infections. 2020; 35: 100684. Available from: doi:10.1016/j.nmni.2020.100684.

[47] Jadhav J, Jadhav Y, Jadhav M, Davane N, Khanavte P. Triple drug combination hydroxychloroquine, Azithromycin, \& zinc to win battle against COVID-19. International Journal of Innovative Science and Research Technology. 2020; 5(6): 915-918. Available from: https://ijisrt.com/triple-drug-combination-hydroxychloroquine-azithromycinzinc-to-win-battle-against-covid19 [Accessed 15th December 2021].

[48] Singh AK, Singh A, Shaikh A, Singh R, Misra A. Chloroquine and hydroxychloroquine in the treatment of COVID-19 with or without diabetes: a systematic search and a narrative review with a special reference to India and other developing countries. Diabetes \& Metabolic Syndrome: Clinical Research \& Reviews. 2020; 14(3): 241246. Available from: doi:10.1016/j.dsx.2020.03.011.

[49] Adeel AA. Perspectives on repositioning chloroquine and hydroxychloroquine for the treatment of COVID-19. Sudanese Journal of Paediatrics. 2020; 20(1): 4-9. Available from: doi:10.24911/SJP.106-1587122398.

[50] Keshtkar-Jahromi M, Bavari S. A call for randomized controlled trials to test the efficacy of chloroquine and hydroxychloroquine as therapeutics against novel coronavirus disease (COVID-19). The American Journal of Tropical Medicine and Hygiene. 2020; 102(5): 932-933. Available from: doi:10.4269/ajtmh.20-0230.

[51] Meo SA, Klonoff DC, Akram J. Efficacy of chloroquine and hydroxychloroquine in the treatment of COVID-19. European Review for Medical and Pharmacological Sciences. 2020; 24(8): 4539-4547. Available from: doi:10.26355/eurrev_202004_21038.

[52] Sinha N, Balayla G. Hydroxychloroquine and COVID-19. Postgraduate Medical Journal. 2020; 96(1139): 550555. Available from: doi:10.1136/postgradmedj-2020-137785.

[53] Mishima E, Anzai N, Miyazaki M, Abe T. Uric acid elevation by favipiravir, an antiviral drug. The Tohoku Journal of Experimental Medicine. 2020; 251(2): 87-90. Available from: doi:10.1620/tjem.251.87.

[54] Cai Q, Yang M, Liu D, Chen J, Shu D, Xia J, et al. Experimental treatment with favipiravir for COVID-19: an open-label control study. Engineering. 2020; 6(10): 1192-1198. Available from: doi:10.1016/j.eng.2020.03.007.

[55] Salehi M, Edalatifard M, Taslimi R, Ghiasvand F, Khajavirad N, Mirfazaelian H. Fighting COVID-19: what are the available options? Advanced Journal of Emergency Medicine. 2020; 4(2s): e65. Available from: doi:10.22114/ ajem.v4i2s.465.

[56] Goldman JD, Lye DCB, Hui DS, Marks KM, Bruno R, Montejano R, et al. Remdesivir for 5 or 10 days in patients with severe COVID-19. The New England Journal of Medicine. 2020; 383(19): 1827-1837. Available from: doi:10.1056/NEJMoa2015301.

[57] Beigel JH, Tomashek KM, Dodd LE, Mehta AK, Zingman BS, Kalil AC, et al. Remdesivir for the treatment of COVID-19 - final report. The New England Journal of Medicine. 2020; 383(19): 1813-1826. Available from: doi:10.1056/NEJMoa2007764.

[58] Lu H. Drug treatment options for the 2019-new coronavirus (2019-nCoV). BioScience Trends. 2020; 14(1): 69-71. Available from: doi:10.5582/bst.2020.01020.

[59] Zhang Y, Zhong Y, Pan L, Dong J. Treat 2019 novel coronavirus (COVID-19) with IL-6 inhibitor: are we already that far? Drug Discoveries and Therapeutics. 2020; 14(2): 100-102. Available from: doi:10.5582/ddt.2020.03006.

[60] Yang M, Hu Z, Yue R. Efficacy and safety of Chinese herbal medicine for Coronavirus disease 2019: a protocol for systematic review and meta-analysis. Medicine. 2020; 99(22): e20157. Available from: doi:10.1097/ MD.0000000000020157.

[61] Osborne V, Davies M, Lane S, Evans A, Denyer J, Dhanda S, et al. Lopinavir-ritonavir in treatment of COVID-19: a dynamic systematic benefit-risk assessment. Medrxiv [Preprint] 2020. Available from: doi:10.1101/2020.05.27.20 114470.

[62] Zhu Z, Lu Z, Xu T, Chen C, Yang G, Zha T, et al. Arbidol monotherapy is superior to lopinavir/ritonavir in treating COVID-19. Journal of Infection. 2020; 81(1): e21-e23. Available from: doi:10.1016/j.jinf.2020.03.060.

[63] El-Aziz TMA, Stockand JD. Recent progress and challenges in drug development against COVID-19 coronavirus 
(SARS-CoV-2) - an update on the status. Infection, Genetics and Evolution. 2020; 83: 104327. Available from: doi:10.1016/j.meegid.2020.104327.

[64] Rodrigues PDFS, Thomaz DV. A brief overview of current drug repurposing approaches for COVID-19 management. Path of Science. 2020; 6(4): 3001-3005. Available from: doi:10.22178/pos.57-1.

[65] Ito K, Ohmagari N, Mikami A, Sugiura W. Major ongoing clinical trials for COVID-19 treatment and studies currently being conducted or scheduled in Japan. Global Health \& Medicine. 2020; 2(2): 96-101. Available from: doi:10.35772/ghm.2020.01034.

[66] Yamaya M, Nishimura H, Deng X, Kikuchi A, Nagatomi R. Protease inhibitors: candidate drugs to inhibit severe acute respiratory syndrome coronavirus 2 replication. The Tohoku Journal of Experimental Medicine. 2020; 251(1): 27-30. Available from: doi:10.1620/tjem.251.27.

[67] Khomich O, Kochetkov S, Bartosch B, Ivanov A. Redox biology of respiratory viral infections. Viruses. 2018; 10(8): 392. Available from: doi:10.3390/v10080392.

[68] Sukhotnik I, Starikov A, Coran A, Pollak Y, Sohotnik R, Shaoul R. Effect of ozone on intestinal epithelial homeostasis in a rat. Rambam Maimonides Medical Journal. 2015; 6(1): e0006. Available from: doi:10.5041/ RMMJ.10181.

[69] Haj B, Sukhotnik I, Shaoul R, Pollak Y, Coran AG, Bitterman A, et al. Effect of ozone on intestinal recovery following intestinal ischemia-reperfusion injury in a rat. Pediatric Surgery International. 2014; 30(2): 181-188. Available from: doi:10.1007/s00383-013-3448-8.

[70] Galiè M, Covi V, Tabaracci G, Malatesta M. The role of Nrf2 in the antioxidant cellular response to medical ozone exposure. International Journal of Molecular Sciences. 2019; 20(16): 4009. Available from: doi:10.3390/ ijms20164009.

[71] Ranaldi GT, Villani ER, Franza L, Motola G. Devils and angels: Ozonetherapy for microcirculation in COVID-19. Frenxiv [Preprint] 2020. Available from: doi:10.31226/osf.io/c2jvt.

[72] Ranaldi GT, Villani ER, Franza L, Motola G. Ozonetherapy: a multirole weapon, topical pathway against SARSCoV-2. Frenxiv [Preprint] 2020. Available from: doi:10.31226/osf.io/n2dup.

[73] Fernández-Cuadros ME, Albaladejo-Florín MJ, Peña-Lora D, Álava-Rabasa S, Pérez-Moro OS. Ozone $\left(\mathrm{O}_{3}\right)$ and SARS-CoV-2: physiological bases and their therapeutic possibilities according to COVID-19 evolutionary stage. SN Comprehensive Clinical Medicine. 2020; 2(8): 1094-1102. Available from: doi:10.1007/s42399-020-00328-7.

[74] Ricevuti G, Franzini M, Valdenassi L. Oxygen-ozone immunoceutical therapy in COVID-19 outbreak: facts and figures. Ozone Therapy. 2020; 5(1): 9014. Available from: doi:10.4081/ozone.2020.9014.

[75] Martínez-Sánchez G, Schwartz A, Di Donna V. Potential cytoprotective activity of ozone therapy in SARS-CoV-2/ COVID-19. Antioxidants. 2020; 9(5): 389. Available from: doi:10.3390/antiox9050389.

[76] Baeza-Noci J, Re L, Menendez S. COVID19 and Ozone Therapy. Version 2.1. Italy: World Federation of Ozone Therapy; 2020.

[77] Kapicibaşi HO, Kiraz HA, Demir ET, Adali Y, Elmas S. Pulmonary effects of ozone therapy at different doses combined with antibioticotherapy in experimental sepsis model. Acta Cirúrgica Brasileira. 2020; 35(6): e202000604. Available from: doi:10.1590/s0102-865020200060000004.

[78] Brownstein D, Richard NG, Rowen R, Drummond JD, Taylor-Eason PA, Brownstein H, et al. A novel approach to treating COVID-19 using nutritional and oxidative therapies. Science, Public Health Policy, and The Law. 2020; 2 : 4-22. Available from: https://www.semanticscholar.org/paper/A-Novel-Approach-to-Treating-COVID-19-Usingand-Brownstein-Ng/c1805feeee6e9e68a68a0a0071e98e67e7062399 [Accessed 15th December 2021].

[79] Valdenassi L, Franzini M, Ricevuti G, Rinaldi L, Galoforo AC, Tirelli U. Potential mechanisms by which the oxygen-ozone $\left(\mathrm{O}_{2}-\mathrm{O}_{3}\right)$ therapy could contribute to the treatment against the coronavirus COVID-19. European Review for Medical and Pharmacological Sciences. 2020; 24(8): 4059-4061. Available from: doi:10.26355/ eurrev_202004_20976.

[80] Rowen RJ, Robins H. A plausible 'penny' costing effective treatment for corona virus - ozone therapy. Journal of Infectious Diseases and Epidemiology. 2020; 6(2): 113. Available from: doi:10.23937/2474-3658/1510113.

[81] Hernández A, Viñals M, Pablos A, Vilás F, Papadakos PJ, Wijeysundera D, et al. Ozone therapy for patients with COVID-19 pneumonia: a quasi-randomized controlled trial. Medrxiv [Preprint] 2020. Available from: doi:10.1101/ 2020.06.03.20117994. 
[82] de Farias JBF, de Farias APF, de Souza AG. Ozone as a complement therapy in the treatment of COVID-19. Revista Brasileira de Fisiologia do Exercício. 2020; 19(2): 5-8. Available from: doi:10.33233/rbfe.v19i2.4116.

[83] Khamis F, Al-Zakwani I, Al Hashmi S, Al Dowaiki S, Al Bahrani M, Pandak N, et al. Therapeutic plasma exchange in adults with severe COVID-19 infection. International Journal of Infectious Diseases. 2020; 99: 214-218. Available from: doi:10.1016/j.ijid.2020.06.064.

[84] Vidyasagar V, Nithsish C. Convalescentplasma as potential therapy for recently emerged novel COVID-19. EPRA International Journal of Research and Development. 2020; 5(4): 412-414. Available from: doi:10.36713/epra2016.

[85] Adeli SH, Asghari A, Tabarraii R, Shajari R, Afshari S, Kalhor N, et al. Therapeutic plasma exchange as a rescue therapy in COVID-19 patients: a case series. Polish Archives of Internal Medicine. 2020; 130(5): 455-458. Available from: doi:10.20452/pamw.15340.

[86] Focosi D, Tang J, Anderson A, Tuccori M. Convalescent plasma therapy for COVID-19: state of the art. Preprints [Preprint] 2020. Available from: doi:10.20944/preprints202004.0097.v7.

[87] Kong Y, Cai C, Ling L, Zeng L, Wu M, Wu Y, et al. Successful treatment of a centenarian with coronavirus disease 2019 (COVID-19) using convalescent plasma. Transfusion and Apheresis Science. 2020; 59(5): 102820. Available from: doi:10.1016/j.transci.2020.102820.

[88] Alzoughool F, Alanagreh LA. Coronavirus drugs: using plasma from recovered patients as a treatment for COVID-19. International Journal of Risk and Safety in Medicine. 2020; 31(2): 47-51. Available from: doi:10.3233/ JRS-201017.

[89] Erkurt MA, Sarici A, Berber İ, Kuku İ, Kaya E, Özgül M. Life-saving effect of convalescent plasma treatment in COVID-19 disease: clinical trial from eastern Anatolia. Transfusion and Apheresis Science. 2020; 59(5): 102867. Available from: doi:10.1016/j.transci.2020.102867.

[90] Verma HK, Farran B, Bhaskar LVKS. Convalescent plasma transfusion a promising therapy for coronavirus diseases 2019 (COVID-19): current updates. Antibody Therapeutics. 2020; 3(2): 115-125. Available from: doi:10.1093/abt/tbaa010.

[91] Murphy M, Estcourt L, Grant-Casey J, Dzik S. International survey of trials of convalescent plasma to treat COVID-19 infection. Transfusion Medicine Reviews. 2020; 34(3): 151-157. Available from: doi:10.1016/ j.tmrv.2020.06.003.

[92] Banwait RS, Salabei JK, Fishman TJ, Iyer UG. Convalescent plasma in COVID-19. HCA Healthcare Journal of Medicine. 2020; 1(3): 139-146. Available from: doi:10.36518/2689-0216.1097.

[93] Yaribeygi H, Sathyapalan T, Atkin SL, Sahebkar A. Molecular mechanisms linking oxidative stress and diabetes mellitus. Oxidative Medicine and Cellular Longevity. 2020; 2020: 8609213. Available from: doi:10.1155/2020/8609213.

[94] Ntyonga-Pono M-P. COVID-19 infection and oxidative stress: an under-explored approach for prevention and treatment? Pan African Medical Journal. 2020; 35(Supp 2): 12. Available from: doi:10.11604/ pamj.2020.35.2.22877.

[95] Smith RE, Ozben T, Saso L. Modulation of oxidative stress: pharmaceutical and pharmacological aspects 2018. Oxidative Medicine and Cellular Longevity. 2019; 2019: 6380473. Available from: doi:10.1155/2019/6380473.

[96] Camini FC, da Silva Caetano CC, Almeida LT, de Brito Magalhães CL. Implications of oxidative stress on viral pathogenesis. Archives of Virology. 2017; 162(4): 907-917. Available from: doi:10.1007/s00705-016-3187-y.

[97] Deslandes A, Berti V, Tandjaoui-Lambotte Y, Alloui C, Carbonnelle E, Zahar JR, et al. SARS-CoV-2 was already spreading in France in late December 2019. International Journal of Antimicrobial Agents. 2020; 55(6): 106006. Available from: doi:10.1016/j.ijantimicag.2020.106006.

[98] Zhang Z, Rong L, Li Y-P. Flaviviridae viruses and oxidative stress: implications for viral pathogenesis. Oxidative Medicine and Cellular Longevity. 2019; 2019: 1409582. Available from: doi:10.1155/2019/1409582.

[99] Mir JM, Maurya RC. Nitric oxide boosters as defensive agents against COVID-19 infection: an opinion. Journal of Biomolecular Structure and Dynamics. 2020; 1-7. Available from: doi:10.1080/07391102.2020.1852969.

[100] Cooke B, Ernst E. Aromatherapy: a systematic review. British Journal of General Practice. 2000; 50(455): 493496. Available from: https://bjgp.org/content/50/455/493/tab-article-info [Accessed 15th December 2021].

[101] Asif M, Saleem M, Saadullah M, Yaseen HS, Al Zarzour R. COVID-19 and therapy with essential oils having antiviral, anti-inflammatory, and immunomodulatory properties. Inflammopharmacology. 2020; 28(5): 1153-1161. 
Available from: doi:10.1007/s10787-020-00744-0.

[102] Almeida A, Faustino MAF, Neves MGPMS. Antimicrobial photodynamic therapy in the control of COVID-19. Antibiotics. 2020; 9(6): 320. Available from: doi:10.3390/antibiotics9060320.

[103] Bui TQ, Loan HTP, My TTA, Quang DT, Thuy BTP, Nhan VD, et al. A density functional theory study on silver and bis-silver complexes with lighter tetrylene: are silver and bis-silver carbenes candidates for SARS-CoV-2 inhibition? Insight from molecular docking simulation. RSC Advances. 2020; 10(51): 30961-30974. Available from: doi:10.1039/D0RA05159D.

[104]Mishra SS, Ranjan S, Sharma CS, Singh HP, Kalra S, Kumar N. Computational investigation of potential inhibitors of novel coronavirus 2019 through structure-based virtual screening, molecular dynamics and density functional theory studies. Journal of Biomolecular Structure and Dynamics. 2021; 39(12): 4449-4461. Available from: doi:10.1080/07391102.2020.1791957.

[105]Hagar M, Ahmed HA, Aljohani G, Alhaddad OA. Investigation of some antiviral n-heterocycles as covid 19 drug: molecular docking and DFT calculations. International Journal of Molecular Sciences. 2020; 21(11): 3922. Available from: doi:10.3390/ijms21113922.

[106] Jordaan MA, Ebenezer O, Damoyi N, Shapi M. Virtual screening, molecular docking studies and DFT calculations of FDA approved compounds similar to the non-nucleoside reverse transcriptase inhibitor (NNRTI) efavirenz. Heliyon. 2020; 6(8): e04642. Available from: doi:10.1016/j.heliyon.2020.e04642.

[107] Sagaama A, Brandan SA, Issa TB, Issaoui N. Searching potential antiviral candidates for the treatment of the 2019 novel coronavirus based on DFT calculations and molecular docking. Heliyon. 2020; 6(8): e04640. Available from: doi:10.1016/j.heliyon.2020.e04640.

[108]Zhang L, Pan K, Zhang X, Sun W. Density functional theory calculation aided screening of SARS-CoV-2 RNA polymerase inhibitors. Hans Journal of Medicinal Chemistry. 2020; 08(02): 29-37. Available from: doi:10.12677/ HJMCe.2020.82005.

[109] Abraham CS, Muthu S, Prasana JC, Armaković S, Armaković SJ, Rizwana FB, et al. Computational evaluation of the reactivity and pharmaceutical potential of an organic amine: a DFT, molecular dynamics simulations and molecular docking approach. Spectrochimica Acta Part A: Molecular and Biomolecular Spectroscopy. 2019; 222: 117188. Available from: doi:10.1016/j.saa.2019.117188.

[110] Parveen S, Alnoman RB, Bayazeed AA, Alqahtani AM. Computational insights into the drug repurposing and synergism of FDA-approved influenza drugs binding with SARS-CoV-2 protease against COVID-19. American Journal of Microbiological Research. 2020; 8(3): 93-102. Available from: doi:10.12691/ajmr-8-3-3.

[111] Pham MQ, Vu KB, Pham TNH, Huong LTT, Tran LH, Tung NT, et al. Rapid prediction of possible inhibitors for SARS-CoV-2 main protease using docking and FPL simulations. RSC Advances. 2020; 10(53): 31991-31996. Available from: doi:10.1039/D0RA06212J.

[112] Mohammadi S, Esmailpour M, Mohammadi M. Chloroquine drug and Graphene complex for treatment of COVID-19. Research Square [Preprint] 2020. Available from: doi:10.21203/rs.3.rs-29418/v1.

[113] Vlasiou MC, Pafiti KS. Screening possible drug molecules for COVID-19. The example of vanadium (III/IV/ V) complex molecules with computational chemistry and molecular docking. Research Square [Preprint] 2020. Available from: doi:10.21203/rs.3.rs-34033/v1.

[114] Joshi T, Joshi T, Sharma P, Mathpal S, Pundir H, Bhatt V, et al. In silico screening of natural compounds against COVID-19 by targeting Mpro and ACE2 using molecular docking. European Review for Medical and Pharmacological Sciences. 2020; 24(8): 4529-4536. Available from: doi:10.26355/eurrev_202004_21036.

[115] Calligari P, Bobone S, Ricci G, Bocedi A. Molecular investigation of SARS-CoV-2 proteins and their interactions with antiviral drugs. Viruses. 2020; 12(4): 445. Available from: doi:10.3390/v12040445.

[116] Samy G, Xavier L. Molecular docking studies on antiviral drugs for SARS. International Journal of Advanced Research in Computer Science and Software Engineering. 2015; 5(3): 75-79. Available from: https://www. researchgate.net/publication/274248683_Molecular_Docking_Studies_on_Antiviral_Drugs_for_SARS [Accessed 15th December 2021].

[117] Islam R, Parves MR, Paul AS, Uddin N, Rahman MS, Mamun AA, et al. A molecular modeling approach to identify effective antiviral phytochemicals against the main protease of SARS-CoV-2. Journal of Biomolecular Structure and Dynamics. 2020; 39(9): 3213-3224. Available from: doi:10.1080/07391102.2020.1761883. 
[118] Mpiana PT, Ngbolua K-N, Tshibangu DST, Kilembe JT, Gbolo BZ, Mwanangombo DT, et al. Identification of potential inhibitors of SARS-CoV-2 main protease from aloe vera compounds: a molecular docking study. Chemical Physics Letters. 2020; 754: 137751. Available from: doi:10.1016/j.cplett.2020.137751.

[119] Hakmi M, Bouricha EM, Kandoussi I, Harti JE, Ibrahimi A. Repurposing of known anti-virals as potential inhibitors for SARS-CoV-2 main protease using molecular docking analysis. Bioinformation. 2020; 16(4): 301307. Available from: doi:10.6026/97320630016301.

[120]El-hoshoudy AN. Investigating the potential antiviral activity drugs against SARS-CoV-2 by molecular docking simulation. Journal of Molecular Liquids. 2020; 318: 113968. Available from: doi:10.1016/j.molliq.2020.113968.

[121] Hosny NM, Sherif Y. Molecular docking study on some isonicotinoyl hydrazide derivatives as potential inhibitors of COVID-19. Letters in Applied NanoBioScience. 2020; 9(3): 1217-1224. Available from: doi:10.33263/ LIANBS93.12171224.

[122] Parvez MSA, Karim MA, Hasan M, Jaman J, Karim Z, Tahsin T, et al. Prediction of potential inhibitors for RNA-dependent RNA polymerase of SARS-CoV-2 using comprehensive drug repurposing and molecular docking approach. International Journal of Biological Macromolecules. 2020; 163: 1787-1797. Available from: doi:10.1016/j.ijbiomac.2020.09.098.

[123] Mukherjee S, Dasgupta S, Adhikary T, Adhikari U, Panja SS. Structural insight to hydroxychloroquine-3C-like proteinase complexation from SARS-CoV-2: inhibitor modelling study through molecular docking and MDsimulation study. Journal of Biomolecular Structure and Dynamics. 2021; 39(18): 7322-7334. Available from: doi: 10.1080/07391102.2020.1804458.

[124]Hussien MA, Abdelaziz AEM. Molecular docking suggests repurposing of brincidofovir as a potential drug targeting SARS-CoV-2 ACE2 receptor and main protease. Network Modeling Analysis in Health Informatics and Bioinformatics. 2020; 9(1): 56. Available from: doi:10.1007/s13721-020-00263-6.

[125] Gonzalez-Paz LA, Lossada CA, Moncayo LS, Romero F, Paz JL, Vera-Villalobos J, et al. Theoretical molecular docking study of the structural disruption of the viral 3CL-protease of COVID19 induced by binding of capsaicin, piperine and curcumin part 1: a comparative study with chloroquine and hydrochloroquine two antimalaric drugs. Research Square [Preprint] 2020. Available from: doi:10.21203/rs.3.rs-21206/v1.

[126] Ong E, Wong MU, Huffman A, He Y. COVID-19 coronavirus vaccine design using reverse vaccinology and machine learning. Biorxiv [Preprint] 2020. Available from: doi:10.1101/2020.03.20.000141.

[127]Li F. Structure, function, and evolution of coronavirus spike proteins. Annual Review of Virology. 2016; 3: 237261. Available from: doi:10.1146/annurev-virology-110615-042301.

[128] National Institute of Allergy and Infectious Diseases. Safety and immunogenicity study of 2019-nCoV vaccine (mRNA-1273) for prophylaxis of SARS-CoV-2 infection (COVID-19). NLM. ClinicalTrials.gov Identifier: NCT04283461, 2020.

[129] National Institutes of Health Clinical Center. Phase I study of a vaccine for severe acute respiratory syndrome (SARS). NLM. ClinicalTrials.gov Identifier: NCT00099463, 2004.

[130] National Institute of Allergy and Infectious Diseases. SARS coronavirus vaccine (SARS-CoV). NLM. ClinicalTrials.gov Identifier: NCT00533741, 2007.

[131] National Institute of Allergy and Infectious Diseases. Phase I dose escalation SARS-CoV recombinant S protein, with and without adjuvant, vaccine study. NLM. ClinicalTrials.gov Identifier: NCT01376765, 2011.

[132] University of Oxford. Safety and immunogenicity of a candidate MERS-CoV vaccine (MERS001). NLM. ClinicalTrials.gov Identifier: NCT03399578, 2018.

[133] Addo M. Safety, tolerability and immunogenicity of vaccine candidate MVA-MERS-S. NLM. ClinicalTrials.gov Identifier: NCT03615911, 2018.

[134]King Abdullah International Medical Research Center. A clinical trial to determine the safety and immunogenicity of healthy candidate MERS-CoV vaccine (MERS002). NLM. ClinicalTrials.gov Identifier: NCT04170829, 2019.

[135] University Medical Center Hamburg-Eppendorf. Safety and immunogenicity of the candidate vaccine MVAMERS-S_DF-1 against MERS (MVA-MERS-S). NLM. ClinicalTrials.gov Identifier: NCT04119440, 2019.

[136] Health Ministry of the Russian Federation. Study of safety and immunogenicity of BVRS-GamVac-Combi. NLM. ClinicalTrials.gov Identifier: NCT04128059, 2019.

[137]Health Ministry of the Russian Federation. Study of safety and immunogenicity of BVRS-GamVac. NLM. 
ClinicalTrials.gov Identifier: NCT04130594, 2019.

[138] Roper RL, Rehm KE. SARS vaccines: where are we? Expert Review of Vaccines. 2009; 8(7): 887-898. Available from: doi:10.1586/erv.09.43.

[139]de Wit E, van Doremalen N, Falzarano D, Munster VJ. SARS and MERS: recent insights into emerging coronaviruses. Nature Reviews Microbiology. 2016; 14(8): 523-534. Available from: doi:10.1038/nrmicro.2016.81.

[140] Samad A, Ahammad F, Nain Z, Alam R, Imon RR, Hasan M, et al. Designing a multi-epitope vaccine against SARS-CoV-2: an immunoinformatics approach. Journal of Biomolecular Structure and Dynamics. 2020; 1-17. Available from: doi:10.1080/07391102.2020.1792347.

[141]Folaranmi T, Rubin L, Martin SW, Patel M, MacNeil JR. Use of serogroup B meningococcal vaccines in persons aged $\geq 10$ years at increased risk for serogroup B meningococcal disease: recommendations of the Advisory Committee on Immunization Practices, 2015. Morbidity and Mortality Weekly Report. 2015; 64(22): 608-612. Available from: https://www.cdc.gov/mmwr/preview/mmwrhtml/mm6422a3.htm [Accessed 15 th December 2021].

[142] AstraZeneca. FDA authorises restart of the COVID-19 AZD1222 vaccine US phase III trial. Available from: $\mathrm{https} / / / \mathrm{www}$.astrazeneca.com/content/astraz/media-centre/press-releases/2020/fda-authorises-restart-of-the-covid19-azd1222-vaccine-us-phase-iii-trial.html [Accessed 15th December 2021]. 